\section{EFEK PENAMBAHAN KITOSAN TERHADAP KARAKTERISTIK FISIKA KIMIA BIOPLASTIK PATI BATANG KELAPA SAWIT}

\author{
*Muhammad Nur Alam ${ }^{1}$ \\ Taqwin Halid $^{2}$ \\ Ilmiati Illing ${ }^{3}$ \\ 1,2,3Kimia Anorganik, \\ Fakultas Sains Universitas \\ Cokroaminoto Palopo \\ *Email : alam.unm@gmail.com
}

\begin{abstract}
Abstrak. Telah dilakukan penelitian untuk mengetahui efek penambahan kitosan terhadap sifat serapan air dan biodegradasi dari bioplastik. Bioplastik dibuat dengan bahan dasar pati batang kelapa sawit menggunakan metode direct mixing dengan penambahan kitosan pada konsentrasi $2 \%, 4$ $\%, 6 \%$. Nilai serapan air rata - rata bioplastik sebesar 22,46\% dengan serapan air terendah sebesar 14,6\% yang diperoleh pada penambahan kitosan $6 \%$ Biodegradasi tertinggi sebesar $76,8 \%$ yang diperoleh pada penambahan kitosan $4 \%$ dalam waktu 15 hari penguburan dalam tanah. Secara umum, semakin besarnya konsentrasi kitosan menyebabkan penurunan serapan air, namun sebaliknya meningkatkan laju biodegradasi bioplastik.
\end{abstract}

Kata Kunci : Batang Kelapa Sawit, Pati Bioplastik, Kitosan, Biodegradasi

\section{INDONESIAN JOURNAL OF FUNDAMENTAL SCIENCES (IJFS)}

\section{E-ISSN: 2621-6728 \\ P-ISSN: 2621-671X}

Submitted: January $21^{\text {th }}, 2018$

Accepted : February, $3^{\text {th }}, 2018$

Abstract. A research has been conducted to investigate the effect of chitosan addition on water uptake and biodegradation properties of bioplastics. Bioplastic was synthesized from starch of palm stem using direct mixing method with chitosan addition at concentration of $2 \%, 4 \%, 6 \%$. The average water uptake of $22.46 \%$ with the lowest water uptake was found to be $14.6 \%$ by the addition of $6 \%$ chitosan. The highest biodegradation was found to be $76.8 \%$ by the addition of $4 \%$ chitosan within 15 days of burial in soil. In general, the greater the concentration of chitosan leads to greater bioplastic biodegradation rate. 


\section{PENDAHULUAN}

Perkembangan teknologi polimer plastik telah membawa banyak manfaat dalam kehidupan manusia. Plastik banyak digunakan baik dalam industri pangan maupun non pangan. Plastik yang banyak digunakan saat ini merupakan hasil sintesis polimer hidrokarbon dari minyak bumi yang terbatas jumlahnya dan tidak dapat diperbaharui, seperti polietilena (PE), polipropilena (PP), polistirena (PS), polivinil klorida (PVC) dan sebagainya (Awadhiya dkk, 2016).

Struktur molekul plastik yang sangat kompleks menyebabkan plastik sulit didegradasi oleh mikroorganisme sehingga terakumulasi dan menimbulkan pencemaran serta kerusakan lingkungan. Banyak limbah plastik yang terkumpul dan tidak terurai sempurna mengakibatkan daya serap tanah terhadap air akan sangat berkurang. Hal tersebut karena plastik terbuat dari bahan-bahan sintetis yang bersifat non biodegradable atau tidak dapat diuraikan secara alami oleh mikroorganisme di dalam tanah (Oktavia dkk, 2015).

Salah satu cara yang dapat dilakukan untuk mengurangi permasalahan lingkungan tersebut yaitu mengembangkan bioplastik. Bioplastik merupakan plastik yang berasal dari bahan alam dan dapat diuraikan oleh mikroorganisme menjadi senyawa yang lebih sederhana. Bahan-bahan yang dapat digunakan salah satunya adalah pati. Telah banyak dilakukan penelitian yang memanfaatkan pati sebagai bahan utama pembuatan bioplastik seperti pati kulit singkong, sagu, kulit pisang, dan sebagainya. Akan tetapi, pembuatan bioplastik dengan memanfaatkan limbah batang kayu kelapa sawit belum banyak dilakukan.

Produk bioplastik berbahan dasar pati memiliki beberapa kelemahan, terutama dari sifat ketahanannya terhadap air dan panas. Hal ini disebabkan karena sifat pati yang mudah menyerap air dan tidak tahan terhadap temperatur tinggi (Sagnelli dkk, 2016). Oleh karena itu, perlu adanya bahan aditif yang mampu mengatasi masalah tersebut. Salah satu bahan aditif yang dapat ditambahkan dalam campuran gel bioplastik adalah kitosan.

Penelitian yang dilakukan oleh Oktavia dkk (2015) menunjukkan bahwa FRL (Film Ramah Lingkungan) dengan penambahan konsentrasi kitosan yang berbeda, memberikan pengaruh nyata terhadap kadar air, ketebalan FRL, ketahanan air dan degradasi FRL. Penggunaan kitosan sebagai bahan aditif dalam pembuatan bioplastik sangat ditunjang oleh sifatnya yang mudah menyatu dengan bahan lain, hidrofobik, dan mudah terdegradasi di alam.

\section{METODE PENELITIAN}

Penelitian ini dilakukan melalui pendekatan eksperimen dengan memanfaatkan sampel dari batang kelapa sawit sebagai material dasar yang ditambahkan dengan kitosan sebagai bahan aditif, gliserol sebagai plasticizer, dan asam asetat glasial 
sebagai pelarut. Penelitian ini dilakukan di laboratorium Bahan Alam Universitas Cokroaminoto Palopo.

Variabel penelitian berupa konsentrasi kitosan sebagai variabel bebas yang divariasikan dari $2 \%, 4 \%$, dan $6 \%$. Sintesis bioplastik menggunakan metode direct mixing yang terdiri dari 4 tahap yaitu preparasi pati batang kelapa sawit, pembuatan larutan stok kitosan, mixing material, dan tahap pencetakan. Selanjutnya, pengujian sampel bioplastik berupa uji ketahanan air dan uji biodegradasi. Standarisasi untuk uji ketahanan air mengacu pada standar ASTM Internasional D570-98 (Standard Test Method for Water Absorption of Plastics), sedangkan Standarisasi untuk uji biodegradasi mengacu pada standar ASTM D-5488-84d (Coniwati, 2014).

\section{HASIL DAN PEMBAHASAN}

\section{Hasil Sintesis Bioplastik}

Bioplastik yang dihasilkan pada penelitian ini berupa film biplastik yang berbentuk flat. Tabel 3.1 menunjukkan karakteristik fisik dari sampel bioplastik. Sampel P1 adalah bioplastik dengan penambahan $2 \%$ kitosan, P2 (penambahan $4 \%$ kitosan), dan $\mathrm{P}_{3}$ (penambahan $6 \%$ kitosan). Berdasarkan hasil pengamatan secara langsung, ketiga sampel bioplastik memiliki permukaan yang halus. Dari segi elastisitas, sampel P3 (6 \% kitosan) memiliki sifat elastisitas yang lebih tinggi daripada sampel P2 dan $\mathrm{P} 1$.

Tabel 1 Hasil Pengamatan Pembuatan Bioplastik

\begin{tabular}{lll}
\hline Sampel Bioplastik & Bentuk & Gambar \\
\hline P1 & - Permukaan halus & \\
(2\% Kitosan) & $\bullet$ Cukup Elastis & \\
\hline P2 & - Permukaan halus & \\
(4\% Kitosan) & $\bullet$ Elastis \\
\hline P3 & - Permukaanhalus & \\
(6\% Kitosan) & $\bullet$ Sangat elastis \\
\hline
\end{tabular}

Sumber: Data primer (2017)

\section{Hasil Uji Karakteristik Bioplastik}

Daya Serap Air (Water Uptake)

Berdasarkan nilai serapan air dari ketiga perlakuan dapat disimpulkan bahwa perlakuan 3 dengan penambahan $6 \%$ kitosan memberikan nilai serapan air paling kecil yaitu 14,8\% dibanding film dengan perlakuan 1 (30,6\%) dan perlakuan 2 (22\%). 
Jika dibandingkan dengan standar ASTM Internasional untuk plastik konvensional polipropilena yang memiliki serapan air 0,01\%, maka nilai serapan air dari bioplastik yang dihasilkan masih sangat jauh. Hal ini menunjukkan bahwa ketahanan terhadap airnya masih rendah jika dibandingkan dengan plastik sintetik komersil. Hasil pengujian ketahanan air disajikan dalam Tabel 2 berikut:

Tabel 2. Hasil Pengamatan Uji Ketahanan Air

\begin{tabular}{cccccc}
\hline & & \multicolumn{3}{c}{ Berat Setelah Perendaman } \\
P & $\begin{array}{c}\text { Berat Awal } \\
\text { (gr) }\end{array}$ & \multicolumn{3}{c}{ (gr) } \\
\cline { 3 - 5 } & & ke-1 & ke' & $10^{\prime}$ ke- & 3 \\
\hline P1 & 0,50 & 0,60 & 0,64 & 0,65 & 30,6 \\
P2 & 0,50 & 0,59 & 0,60 & 0,61 & 22 \\
P3 & 0,50 & 0,58 & 0,57 & 0,57 & 14,8 \\
\hline
\end{tabular}

Sumber: Data primer (2017)

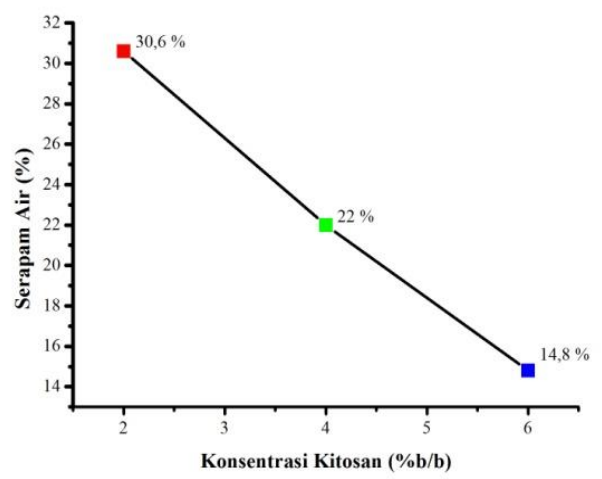

Chart 1. Grafik hubungan konsentrasi kitosan (\% b/b) dan serapan air (\%).

Chart 1 menunjukkan bahwa Nilai ketahanan air dari masing-masing perlakuan dapat dijelaskan bahwa semakin meningkat konsentrasi kitosan maka nilai serapan airnya semakin kecil. Hal ini menunjukkan bahwa semakin kecil nilai serapan airnya maka semakin meningkat ketahanan air bioplastik tersebut. Penurunan nilai serapan air seiring dengan kenaikan konsentrasi kitosan disebabkan karena kitosan bersifat hidrofobik (tidak suka air). Kitosan memiliki sifat tidak larut dalam air dan pelarut organik karena kitosan memiliki struktur kristal yang tersusun oleh ikatan hidrogen intramolekuler dan intermolukuler (Vlacha dkk, 2016).

Uji Biodegradasi

Hasil (Tabel 3) yang telah diamati selama 15 hari pada penguburan dalam tanah untuk semua film bioplastik, terlihat bahwa semua film bioplastik mengalami pengurangan berat dengan persentase yang berbeda-beda setiap 5 hari penguburan. 
Tabel 3. Hasil Pengamatan Uji Biodegradasi

\begin{tabular}{|c|c|c|c|c|}
\hline Harike- & Perlakuan & $W_{1}(g)$ & $W_{2}(g)$ & W (\%) \\
\hline \multirow{3}{*}{5} & $\mathrm{P} 1$ (2\% CS) & 0,212 & 0,168 & 20,7 \\
\hline & P2 (4\% CS) & 0,190 & 0,163 & 14,2 \\
\hline & $\mathrm{P}_{3}(6 \% \mathrm{CS})$ & 0,286 & 0,267 & 6,6 \\
\hline \multirow{3}{*}{10} & $\mathrm{P} 1$ (2\% CS) & 0,212 & 0,089 & 58 \\
\hline & $\mathrm{P}_{2}(4 \% \mathrm{CS})$ & 0,190 & 0,055 & 71 \\
\hline & P3 (6\% CS) & 0,286 & 0,161 & 43,7 \\
\hline \multirow{3}{*}{15} & $\mathrm{P} 1$ (2\% CS) & 0,212 & 0,078 & 63,2 \\
\hline & P2 (4\% CS) & 0,190 & 0,044 & 76,8 \\
\hline & $P_{3}(6 \%$ CS $)$ & 0,286 & 0,127 & 55,5 \\
\hline
\end{tabular}

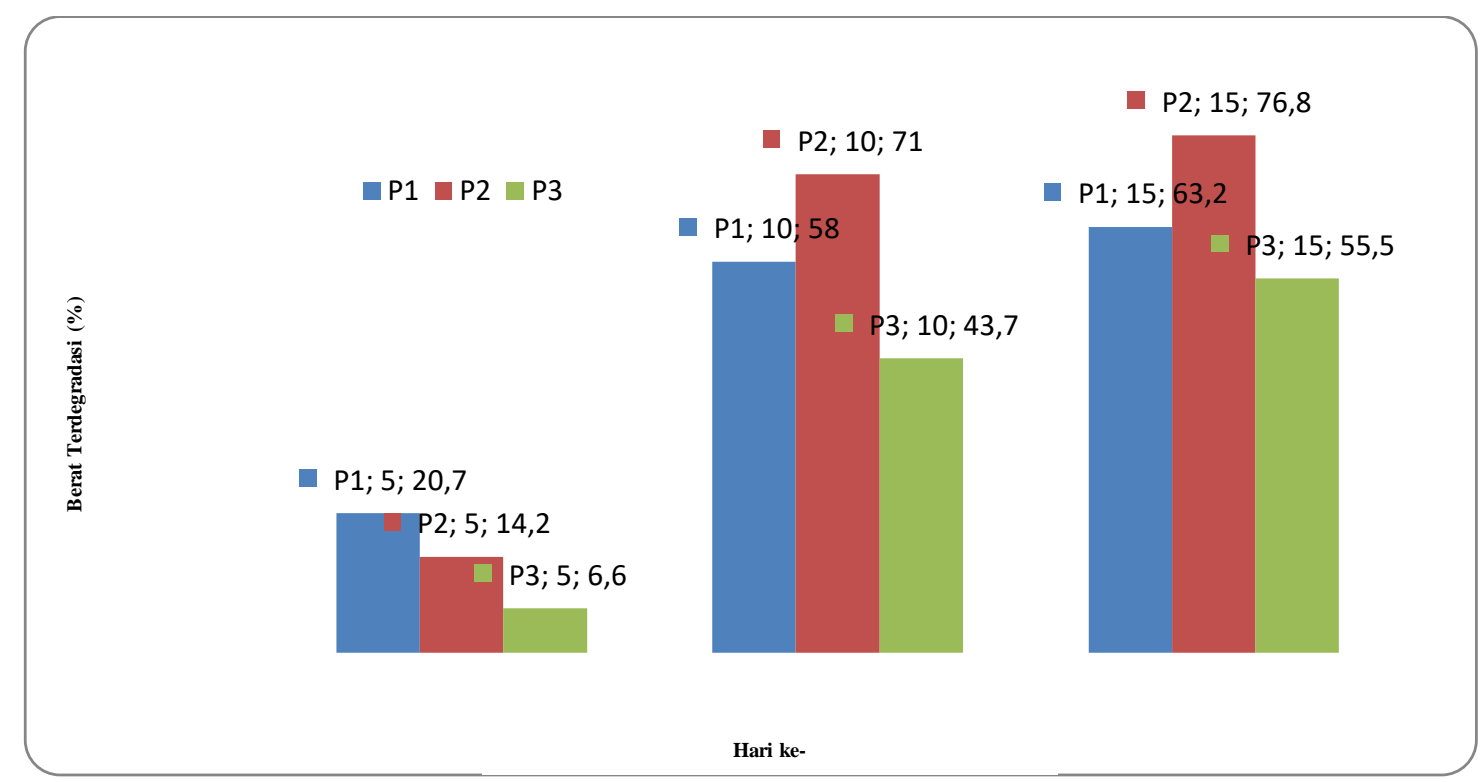

Chart 2. Hubungan Konsentrasi Kitosan dan lama penguburan Terhadap Laju Biodegradasi.

Berdasarkan nilai pengurangan berat untuk setiap film bioplastik selama 15 hari dapat disimpulkan bahwa film bioplastik $\mathrm{P}_{3}$ (6\% kitosan) memiliki nilai pengurangan berat terkecil yaitu 55,5\% (hari ke-15) dan film bioplastik P2 (4\% kitosan) memiliki nilai pengurangan terbesar yaitu 76,8\% (hari ke-15). Chart 2 secara jelas menunjukkan bahwa semakin bertambahnya konsentrasi kitosan maka pengurangan berat dari film bioplastik semakin kecil. Ini disebabkan karena kitosan bersifat hidrofobik dan memiliki sifat antimikrobakterial sehingga mengalami kerusakan dan penyusutan massa lebih lama (Vlacha dkk, 2016).

Lebih lanjut, chart tersebut juga memperlihatkan hubungan antara lamanya penguburan dengan persentase berat sampel yang terdegradasi. Semakin lama 
penguburan, berat sampel yang terdegradasi juga semakin besar. Berdasarkan standar Internasional (ASTM 5336) lamanya film plastik terdegradasi (biodegradasi) untuk plastik PLA dari Jepang dan PCL dari Inggris membutuhkan waktu 60 hari untuk dapat terdegradasi secara keseluruhan (100\%). Dalam penelitian ini besar degradasi dengan melihat pengurangan berat dari film dengan perlakuan $\mathrm{P}_{1}, \mathrm{P}_{2}$, dan P3 selama 15 hari secara berturut-turut adalah 63,2\%, 76,8\%, dan 55,5\%.

Hasil tersebut membuktikan bahwa biodegradasi dari semua film bioplastik telah memenuhi standar yang berlaku, bahkan film dengan pengurangan berat terkecil yaitu film dengan perlakuan $\mathrm{P}_{3}$ mengalami pengurangan berat sebesar $55,5 \%$ hanya dalam waktu 15 hari.

\section{KESIMPULAN}

Penambahan bahan aditif kitosan dengan konsentrasi yang berbeda memberikan efek yang signifikan terhadap sifat ketahanan air dan biodegradabilitas bioplastik. Ketahanan air bioplastik semakin tinggi seiring dengan meningkatnya konsentrasi kitosan, yang dibuktikan dengan semakin rendahnya daya serap air. Namun sebaliknya, sifat biodegradabilitas semakin menurun dengan meningkatnya konsentrasi kitosan.

\section{DAFTAR PUSTAKA}

Awadhiya., dkk. 2016. Crosslinking of agarose bioplastic using citric acid. Carbohydrate Polymers. Vol 5. No. 40.

Coniwanti, P., dkk. 2014. Pembuatan Plastik Biodegradable dari Pati Jagung dengan

Penambahan Kitosan dan Pemlastis Gliserol. Jurnal Teknik Kimia. Vol. 20, No. 4.

Oktavia, C., dkk. 2015. Pengaruh Penambahan Kitosan Terhadap Beberapa Karakteristik Film Ramah Lingkungan (FRL) Berbasis Pati Sagu (Metroxylon sp.). Sagu. Vol. 14, No. 2.

Sagnelli, D., dkk. 2016. Plant - crafted Starches for Bioplastics Production. Carbohydrate Polymers. Vol. 152. $398-408$.

Vlacha, M., dkk. 2016. On the efficiency of oleic acid as plasticizer of chitosan/clay nanocomposites and its role on thermo - mechanical, barrier and antimicrobial properties- Comparison with glycerol. Food Hydrocolloids. Vol. 57. 10-19. 